\title{
Diffusion tensor imaging of formalin fixed infarcted porcine hearts: a comparison between $3 T$ and $1.5 T$
}

\author{
R Mazumder ${ }^{1 *}$, S Choi ${ }^{2}$, B Raterman², BD Clymer ${ }^{1}$, A Kolipaka ${ }^{2,3}$, RD White ${ }^{2,3}$ \\ From 16th Annual SCMR Scientific Sessions \\ San Francisco, CA, USA. 31 January - 3 February 2013
}

\section{Background}

Diffusion Tensor Imaging (DTI) quantifies the amount of anisotropic diffusion exhibited by biological tissues. Processing DTI images allow a 3D visualization of the fiber architecture by tracking the fiber trajectories within the tissue. Experimental evidence has shown that the myocardium undergoes remodeling as myocardial infarction progresses over time[1]. The aim of this study is to investigate and compare the fiber architecture in an infarcted porcine heart using DTI at $1.5 \mathrm{~T}$ and $3 \mathrm{~T}$, to analyze the effect of high field magnets in imaging.

\section{Methods}

Ex-vivo DTI was performed on an infracted pig heart on 1.5T (Avanto, Siemens Healthcare, Germany) and 3T (Tim Trio, Siemens Healthcare, Germany) MRI scanners. Infarcts were created in the apex region (Fig 1) by occluding the left anterior descending coronary artery. After 22 days, the hearts were dissected and formalin fixed for 6 months. A diffusion-weighted echo planar imaging sequence was used to acquire multi-slice short axis views covering the ventricles in the excised heart. Imaging parameters included: diffusion encoding directions $=256$; $\mathrm{TE}=90 \mathrm{~ms} ; \mathrm{TR}=7000(1.5 \mathrm{~T}), 6600(3 \mathrm{~T}) \mathrm{ms}$; slice thickness $=2 \mathrm{~mm}$; matrix $=128 \times 128$; FOV $=256 \times 256 \mathrm{~mm} 2$; $\mathrm{b}$-values $=0,1000 \mathrm{~s} / \mathrm{mm} 2$; slices $=37(1.5 \mathrm{~T}), 42(3 \mathrm{~T})$; isotropic resolution of $2 \times 2 \times 2 \mathrm{~mm}$. The images were masked to segment the left ventricular myocardium (LVM). Explore DTI [2], was used to obtain a tensor map and track the fibers using a deterministic algorithm. For this analysis, fractional anisotropy (FA) and the angle between the longest eigenvectors (V1) of the two

'Department of Electrical and Computer Engineering, The Ohio State University, Columbus, OH, USA

Full list of author information is available at the end of the article

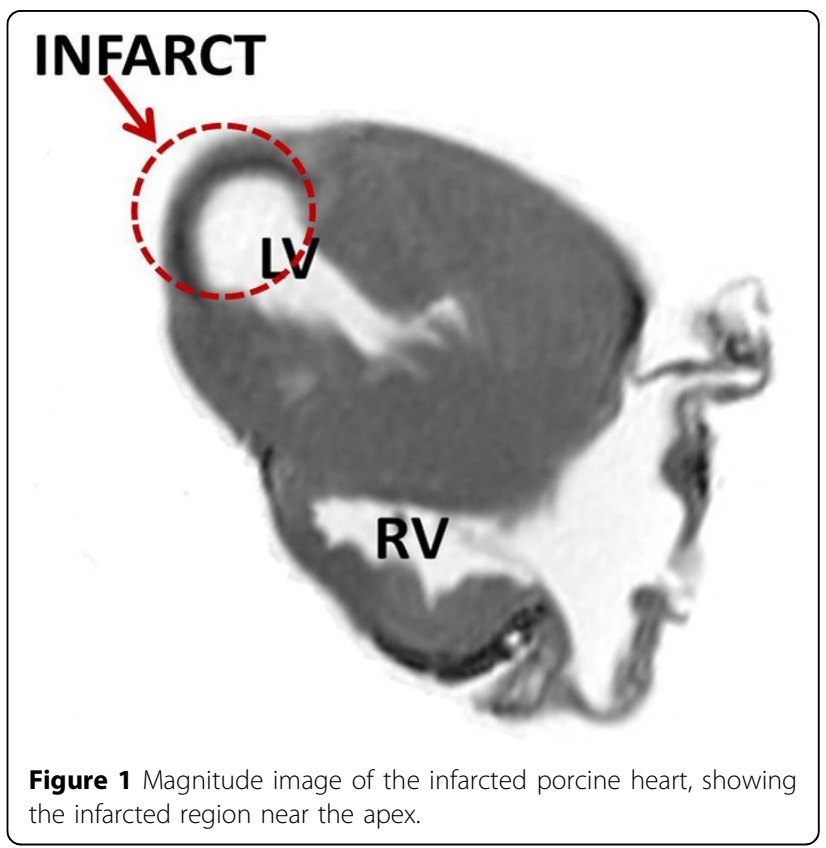

successive voxels were set to 0.2 and 45 degrees respectively. The lower limit of the length of the fibers was varied from $2 \mathrm{~mm}$ to $30 \mathrm{~mm}$ to see the corresponding change in fiber tracts near the infracted region of the LVM obtained from both $1.5 \mathrm{~T}$ and $3 \mathrm{~T}$ scanners.

\section{Results}

Fig 1 shows the magnitude image displaying the infarct with thin myocardial wall. Fig 2 displays 3D visualization of the fiber tracts in the LVM. In Fig 2 the upper row and the lower row displays data from $3 \mathrm{~T}$ and $1.5 \mathrm{~T}$ scanners respectively. From left to right the lower limit of the fiber length was varied in the analysis to track the short
C Biomed Central

(c) 2013 Mazumder et al; licensee BioMed Central Ltd. This is an Open Access article distributed under the terms of the Creative Commons Attribution License (http://creativecommons.org/licenses/by/2.0), which permits unrestricted use, distribution, and reproduction in any medium, provided the original work is properly cited. 


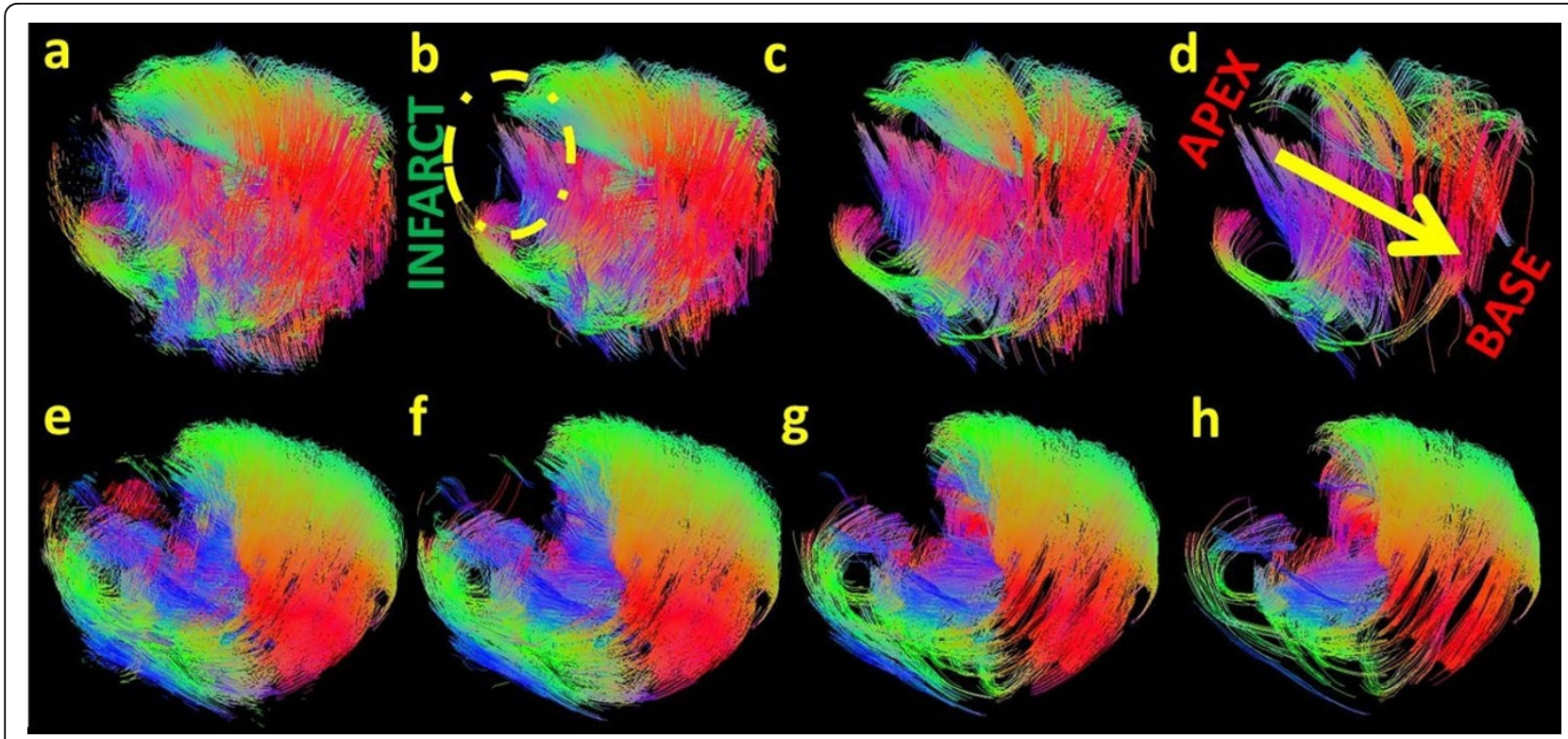

Figure 23 D volumetric representation of fiber tracts in an infarcted porcine myocardium. First row (a-d) and second row (e-h) displays data from 3T and 1.5T MRI scanners respectively. In a row, left indicates 4 different ranges of fibers tracked. a),e) 2-500 mm b),f) 10-500 $\mathrm{mm} \mathrm{c),g)} \mathrm{20-}$ $500 \mathrm{~mm}$ and d),h) 30-500 $\mathrm{mm}$. The direction of the yellow arrow on d indicates the progression from apex to base of the myocardium. The color code denotes the direction of fiber orientation; Green, red and blue corresponds to the $x, y$ and $z$ directions of the image respectively. At the apex, we observe disarrayed shorter fibers identifying the infarcted region and the fibers eventually vanish with increase in the lower limit of the fiber length from left to right in both the datasets.

disarrayed fibers near the infarct (the apex of the heart). Comparing the extreme left column (tracking length range: $2-500 \mathrm{~mm}$ ) to the extreme right column (tracking length range: $30-500 \mathrm{~mm}$ ), we see that more fibers are tracked at the apex of the heart when shorter fiber lengths are included.

\section{Conclusions}

From this preliminary study we observe that the fibers from both the scanners are consistent in terms of the lengths being short and disarrayed around the infracted region compared to the rest of the LVM. We also observe that in the data from the $1.5 \mathrm{~T}$ scanner fibers tracked are smoother and more in number compared to the data from the $3 \mathrm{~T}$ scanner. However, more studies are warranted to confirm our analogy and establish the technique.

\section{Funding}

\section{Author details}

'Department of Electrical and Computer Engineering, The Ohio State University, Columbus, OH, USA. ${ }^{2}$ Department of Radiology, The Ohio State University Wexner Medical Center, Columbus, OH, USA. ${ }^{3}$ Department of Internal Medicine, Division of Cardiology, The Ohio State University Wexner Medical Center, Columbus, OH, USA.

Published: 30 January 2013

\section{References}

1. St. Martin G, et al: Circulation 2000, 101(25):2981-88.

2. Leemans $\mathrm{A}$, et al: 17th ISMRM 3537.

\section{doi:10.1186/1532-429X-15-S1-W34}

Cite this article as: Mazumder et al: Diffusion tensor imaging of

formalin fixed infarcted porcine hearts: a comparison between 3T and 1.5T. Journal of Cardiovascular Magnetic Resonance 2013 15(Suppl 1):W34.

\section{Submit your next manuscript to BioMed Central and take full advantage of:}

- Convenient online submission

- Thorough peer review

- No space constraints or color figure charges

- Immediate publication on acceptance

- Inclusion in PubMed, CAS, Scopus and Google Scholar

- Research which is freely available for redistribution
Biomed Central 